\title{
The effect of fuel injection equipment on the dispersed phase of water-in- diesel emulsions
}

\author{
Mhadi A. Ismael a,b, , Morgan R. Heikala,c, A. Rashid A. Aziz ${ }^{\mathrm{a}}$, Firman Syahª, Ezrann Z. Zainal A.a, \\ Cyril Crua ${ }^{\circ}$ \\ ${ }^{a}$ Center for Automotive Research and Electric Mobility, Universiti Teknologi PETRONAS, Perak, Malaysia \\ ${ }^{b}$ Mechanical Engineering Department, University of Bahri, Khartoum Bahri, Khartoum, Sudan \\ ${ }^{c}$ Advanced Engineering Centre, University of Brighton, Brighton BN2 4GJ, United Kingdom
}

\begin{abstract}
Water-in-diesel emulsions are known to lead to micro-explosions when exposed to high temperatures, thereby offering a technology that could improve the mixing of fuels with the ambient gas. The number and size distributions of the dispersed phase have a significant effect on both the long-term stability of the emulsion and the probability of micro-explosion inside an engine. Although the elevated pressures, temperatures, and shear found in high-pressure pumps and common-rail injector nozzles are likely to alter the properties of emulsions, the effect of these engine components on the injected emulsion are not known. To address this issue we sampled an emulsion at several locations within the injection system, from the fuel tank to the injector nozzle, and measured the evolution of the droplet size distribution of the emulsion's dispersed phase. We varied the water mass fraction (5, 10 and $15 \%$ by volume) of the emulsion and the injection pressure (500, 1000 and 1500 bar), imaged the samples using a high-resolution microscope and extracted the droplet size distribution using a purpose-built image processing algorithm. Our measurements reveal that the dispersed droplet sizes reduce significantly after the emulsion is compressed by the high-pressure fuel pump, and again after being injected through the nozzle's orifices. Additionally, the dispersed droplet sizes measured from the pump's return and injector return to the fuel tank were also smaller than the initial size, suggesting that the physical and calorific properties of the emulsion in the fuel tank can change significantly with time. Hence we propose that differences in injection equipment and engine testing duration may contribute to some of the disagreements in the literature regarding the effect of emulsified fuels on engine emissions and fuel efficiency. The engine performance and energy efficiency of vehicle fleets that use emulsified fuels will vary with engine running time, thus potentially inducing a drift in the engine performance and exhaust emissions. This investigation also suggests that, in order to be representative of actual injection conditions, fundamental studies of the micro-explosion of emulsion droplets should be performed using much smaller dispersed droplet sizes than those normally found in an unused emulsion.
\end{abstract}

Keywords: Water-in-diesel, macro-emulsions, nano-emulsions, micro-explosion

\footnotetext{
* Corresponding author: mhadi_g03348@utp.edu.my
} 


\section{Introduction}

By combining high thermal efficiency and high energy density, diesel engines have dominated medium and heavy duty transportation. However, they remain a significant source of environmental pollution and a concern for air quality in urban areas. To mitigate these issues and meet stringent emission regulations, engine manufacturers have used a range of hardware-based strategies, such as high-pressure fuel injection, particulate filters, exhaust gas recirculation, fast-response injectors and multiple injection strategies [1]. Whilst these technologies have significantly reduced the tailpipe emissions of new modern vehicles, they remain both expensive and generally unsuitable for retrofitting on existing vehicle fleets. Hence there is a need to identify fuelbased technologies that could enable the production of clean low-cost heavy-duty powertrains, and provide a way to reduce emissions from existing vehicles, particularly for developing countries where the cost of state-of-the-art hardware technologies may be prohibitive.

Water-in-diesel emulsions have received significant attention due to their potential simultaneously reduce NOx and particulate emissions. However, despite evidence of some beneficial effects the technology needs more research to improve the emulsified fuels' stability and to better understand their interaction with the fuel injection hardware. Different methods have been implemented to introduce water into the engine cylinder, including through injection into the intake manifold [2], the direct injection of water into the combustion chamber [3,4] and the emulsification of water into diesel prior to injection into the chamber [5-13]. More recently the emulsification of diesel with water in real-time has demonstrated the possibility of producing on-board water-in-diesel emulsions without the need for surfactants $[14,15]$. Although a reduction of emissions was obtained using the water injection methods, the engine suffered from corrosion and required extensive modifications. Therefore the use of wateremulsified diesel fuel could be a more efficient approach for the reduction of exhaust emissions while improving engine performance, without requiring any engine modification. Diesel and biodiesel-diesel emulsions with $15 \%$ water concentration were found to increase break thermal efficiency by approximately $6 \%$, with a $30 \%$ reduction in NOx and smoke and a 70\% reduction in unburnt hydrocarbons [16]. Brake specific fuel consumption (BSFC) increases due to the lower calorific value of the emulsions [17] as water displaces diesel fuel. However, computing BSFC using the nominal water content of an emulsion neglects the possibility that the engine's fuel system could promote de-emulsification and the loss of water through heating and shearing of the emulsion. As a result, the actual proportion of water in the emulsion injected inside the engine cylinder could be lower than that of the "fresh" unused emulsion. If strictly the amount of fuel within the emulsion is considered to compute the BSFC then fuel consumption is found to reduce when compared to neat diesel [18]. Hence, a better understanding of the effect of the fuel injection hardware on the properties of the emulsions is essential if correct fuel efficiency calculations are to be performed.

Interestingly, some research shows that emulsifying diesel with wet algal biomass instead of water could produce reductions of NOx and particulate emissions while also increasing the calorific value of the emulsion [19]. An increase of water concentration to $30 \%$ results in longer ignition delays due to the lower volatility and higher viscosity of the dispersed phase [20]. The vaporization of the emulsion's water seems to reduce in-cylinder temperature, thereby reducing NOx formation [21, 19]. Soot emissions also reduce through the increased formation of hydroxyl radicals when a water-in-diesel emulsions are subjected to high temperature, which increase the oxidization rate of the soot [22]. Research shows that effects of emulsions on NOx emissions [23] and engine efficiency [24] are significantly related to the properties of the dispersed water droplets, with smaller dispersed 
droplet sizes leading to improvements in combustion and emissions. Yang et al. [9] argued that smaller dispersed water droplet sizes accelerate flame propagation and therefore shorten the combustion duration. There is also some speculation in the literature that the combustion process is also improved through an increased secondary atomization [25, 26], leading to better air-fuel mixing [27]. The potential for water-in-diesel emulsions improving the secondary atomization process is believed to be attributed to the phenomena of puffing and micro-explosion. Micro-explosion is caused by the rapid breakup of a droplet due to the different volatility of the diesel (continuous phase) and water (dispersed phase), leading to the accelerated breakup of the emulsion droplets into smaller droplets. The puffing phenomenon is related to some of the dispersed water bursting out of the emulsion droplets [28]. Both phenomena enhance the effective fuel droplet size distribution, air-fuel mixing, and ultimately the fuel efficiency [29]. The speculation that micro-explosion and puffing improve secondary atomization and combustion in engines [30] seem mostly based on indirect evidence that increased spray dispersion angle and penetration [25] result in longer ignition delay, which in turn enhances the air-fuel mixing [9, 32]. Despite these findings only few studies provide direct observations of droplet micro-explosions in conventional sprays [31, 33-35] and during combustion $[36,37]$.

Micro-explosion is a particularly fast process which cannot be captured easily at engine operating conditions. Hence, single droplet experiments are often used to facilitate the observation of these events and to develop hypotheses on the relation with the performance of emulsions in engines [38-40]. Observations of the occurrence of micro-explosion for isolated emulsion droplets showed that these events are influenced by water concentration, surfactant type, dispersed water droplets size and temperature [41, 42]. Some researchers observed that the intensity of micro-explosions increased with water content $[43,44]$ as well as with the droplet size of the dispersed water phase. Fine dispersed droplets (1-2 $\mu \mathrm{m}$ diameter) did not give rise to micro-explosion [45], and the optimum dispersed droplet size was found to be in the order of $5 \mu \mathrm{m}$ [46]. The reason for fine dispersed water droplets to inhibit or delay micro-explosion is believed to be due to their lower coalescence rate [42, 47]. A particular limitation of these direct observation of micro-explosion events is that the size of the isolated emulsion droplets tend to be several orders of magnitude larger than the droplets found in typical diesel sprays.

The size of the dispersed water droplets is a good indicator of de-emulsification, hence it can play significant role in improving our understanding of the emulsion properties and its evolution through the fuel injection system. Therefore, to control the micro-explosion and energy efficiency of emulsified fuels it is essential to control the number and size distributions of the dispersed phase from the tank through to the injector. These characteristics are highly dependent upon the water concentration in the emulsion [48], as well as the emulsion production method. For example using a mechanical stirrer (average droplet size $\sim 30 \mu \mathrm{m}$ ), decreases breakup rate and increases coalescence rate resulting in larger droplet sizes [45, 49]. While using a homogenizer (average droplet size $\sim 2 \mu \mathrm{m}$ ), the emulsions are subjected to intense pressures, temperatures and shear flow fields, therefore, the coalescence rate was found to be even higher with increased water evaporation before injection in the engine [50].

Recent theoretical models for the mixing characteristics of water-in-diesel emulsions have demonstrated the importance of the emulsion's density [51], the temperature distribution of the continuous phase [52], and the size distribution of the dispersed phase [28]. However, direct evidence of the impact of the fuel injection system on the dispersed phase has been sorely missing, despite the significant pressures, temperatures and shear imposed on the fuel by several hardware components. Improving our understanding of the evolution of the emulsion's 
properties throughout the fuel injection equipment (FIE) is essential for the validation of numerical simulations of in-cylinder micro-explosion of water-in-diesel fuels.

In this article we address some of these limitations, and show that both the high-pressure pump and injector nozzle significantly modify the size distribution of the dispersed phase. We show that the high-pressure pump shifts the dispersed water droplets to a smaller mean diameter (Section 3.1). Hence the fuel that is returned to the fuel tank (from the pump, common-rail and injector returns) is different from the initial emulsified blend, thus inducing a progressive change of the physical and calorific properties of the fuel in the vehicle's tank. We also show that the injector nozzle further shifts the dispersed water droplets to an even smaller mean diameter. A quantitative analysis of the emulsions' density and dispersed water volume demonstrates that although a large proportion of the water could no longer be detected optically, it still remained within the fuel either as dispersed water or as a nano-emulsion (Section 3.2). This finding indicates that the emulsion injected inside the cylinder has a different dispersed phase size distribution compared to the fresh blend. As a result, and to be comparable to inengine investigations, the boundary conditions for fundamental experimental and numerical studies on the behavior of water-in-diesel droplets should be set using a much smaller dispersed droplet size than that found in unused emulsified fuel.

\section{Materials and methods}

\subsection{Stability and physical properties of emulsified blends}

The density and viscosity of the neat diesel and emulsions were measured using an Anton Paar density meter (DMA 4500M) and an Anton Paar viscometer (Lovis 2000M). The surface tension was measured by the pendant drop method (DataPhysics OCA 15EC), and the calorific value was obtained using an isoperibol calorimeter (Leco AC-350). The properties of all fuels tested are shown in Table 1.

The emulsions were custom-blended for this study with a mechanical stirrer using a reference diesel fuel, surfactant and water concentrations of 5, 10 and $15 \%$ by volume. The kinetic stability of an emulsion represents its ability to resist separation into diesel and water, which naturally occurs through flocculation, sedimentation and coalescence of the dispersed phase [53-55]. To characterize the stability of these custom-blended water-indiesel emulsions we performed a centrifugal test followed by a gravitational stability test. The samples were centrifuged for $10 \mathrm{~min}$ at $1000 \mathrm{rpm}$, and then stored. The samples were inspected every hour for the first 7 hours, and then at 24-hour intervals for 7 days, to record the de-emulsification of the blends (Figure 1). All samples were stable for the initial 2 hours, and then exhibited some de-emulsification after 7 hours, through both sedimentation (water droplets settling downwards) and creaming (diesel droplets settling into a top layer). After 7 days all samples showed significant separation of the emulsions, with the samples that contained the highest concentrations of water resulting in the most significant sedimentation.

Table 1. Properties of neat diesel and water-in-diesel emulsions

\begin{tabular}{ccccc}
\hline $\begin{array}{c}\text { Water content } \\
(\% \mathbf{o v} / \mathbf{v})\end{array}$ & $\begin{array}{c}\text { Density at } 25^{\circ} \mathbf{C} \\
\left(\mathbf{k g} / \mathbf{m}^{\mathbf{3}}\right)\end{array}$ & $\begin{array}{c}\text { Viscosity at } \mathbf{4 0}{ }^{\circ} \mathbf{C} \\
\left(\mathbf{m m}^{\mathbf{2}} / \mathbf{s}\right)\end{array}$ & $\begin{array}{c}\text { Calorific value } \\
(\mathbf{M J} / \mathbf{k g})\end{array}$ & $\begin{array}{c}\text { Surface tension } \\
(\mathbf{N} . \mathbf{m})\end{array}$ \\
\hline 0 (neat diesel) & 825 & 3.21 & 43.20 & 27.1 \\
\hline
\end{tabular}




\begin{tabular}{ccccc}
\hline 5 & 841 & 5.06 & 42.09 & 32.1 \\
\hline 10 & 850 & 8.33 & 39.25 & 31.3 \\
\hline 15 & 858 & 9.35 & 36.30 & 26.6 \\
\hline
\end{tabular}

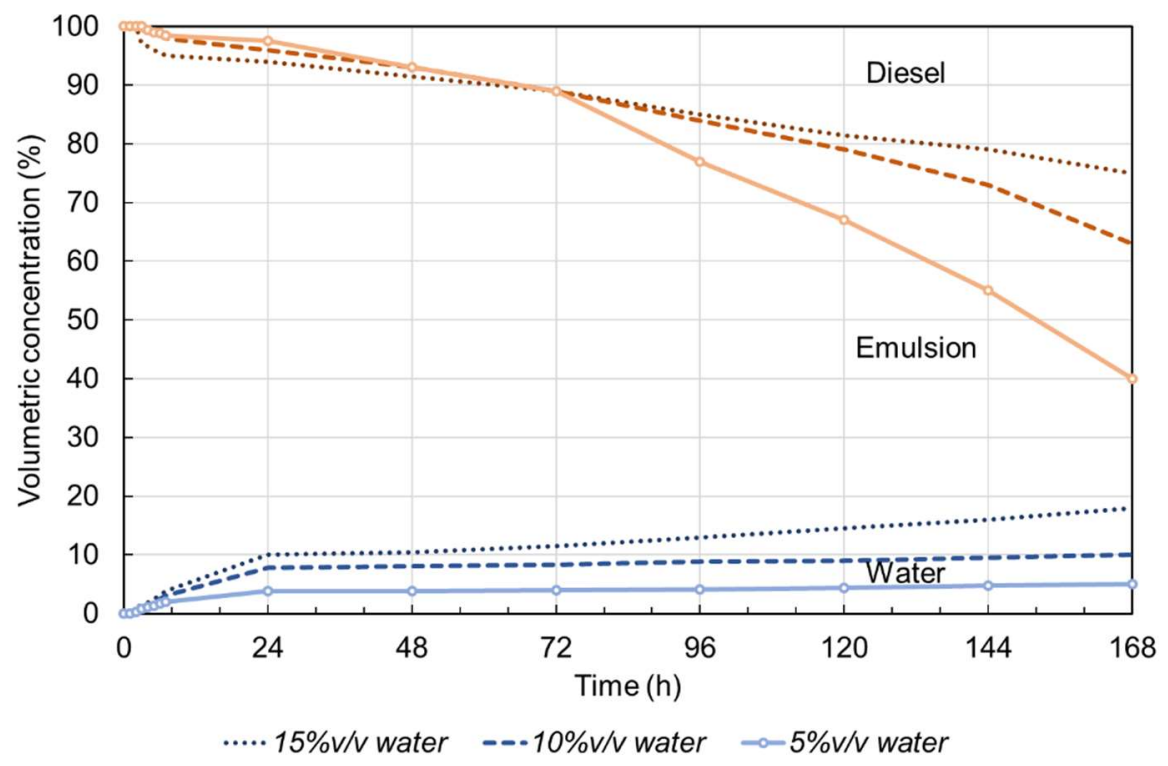

Figure 1. De-emulsification curves for the water-in-diesel emulsions with 5, 10 and 15\% water content by volume. All samples were stable for the initial 2 hours, and then exhibited some de-emulsification after 7 hours. After 7 days, all samples showed significant separation of the emulsions, with the samples that contained the highest concentrations of water resulting in the most significant sedimentation.

\subsection{Experimental setup}

\subsubsection{Fuel injection system}

A common-rail, electronically-controlled injection system was used to generate and induce the high injection pressure sprays into the samples collector. The experimental setup (Figure 2) used in the present study is the same as that of the authors' previous work [56]. This injection system provided flexibility in controlling the injection timing, injection duration and the rail pressure. The fuel injection equipment included: an electric motor, a highpressure fuel pump (Denso HP3 294000-0354) rated at $180 \mathrm{MPa}$, a high-pressure delivery pipe, a common rail, a regulator valve, a pressure gauge, a diesel injector and an injector driver. The fuel injector used for this study was a solenoid valve servo-actuated Denso injector with a 6-hole nozzle with orifice diameters of $0.2 \mathrm{~mm}$. The injection duration was kept at $3 \mathrm{~ms}$ for all the experiments. Two thermocouples (K-type) were used to measure the fuel temperature after the return connections of the high-pressure pump and common rail.

In order to investigate the effect of the fuel injection equipment on the properties of the emulsion, we sampled the fuels at several key points within the system. The sampling locations (Figure 2) included the fuel tank (S1), the return from the high-pressure pump (S2), the common-rail (S3), the return from the injector (S4), and the fuel spray (S5). We selected these locations to discriminate between the effects of the high pressures, temperatures, and shear found in the various components of the fuel system. Note that we removed the return connections from the pump, common-rail, and injector back to the tank. This was done to avoid cross-contamination of the samples, 
and to ensure that the properties of the emulsion in fuel tank would not change with time. This enabled us to relate the individual contributions of each component of the FIE to changes in the emulsion properties. One limitation of our study is that the components of the fuel injection equipment could not be maintained at the temperatures found in a vehicle. In particular it was not possible to replicate the temperatures and gas pressures normally found inside a combustion chamber (sample S5) because under these conditions the fuel would have evaporated and combusted. Since higher engine component temperatures are expected to accelerate the de-emulsification and water evaporation $[30,57,58]$, our study underestimates the degradation of the emulsion. It is interesting to note that the de-emulsification we observed is likely to be much more severe under actual engine operating conditions.

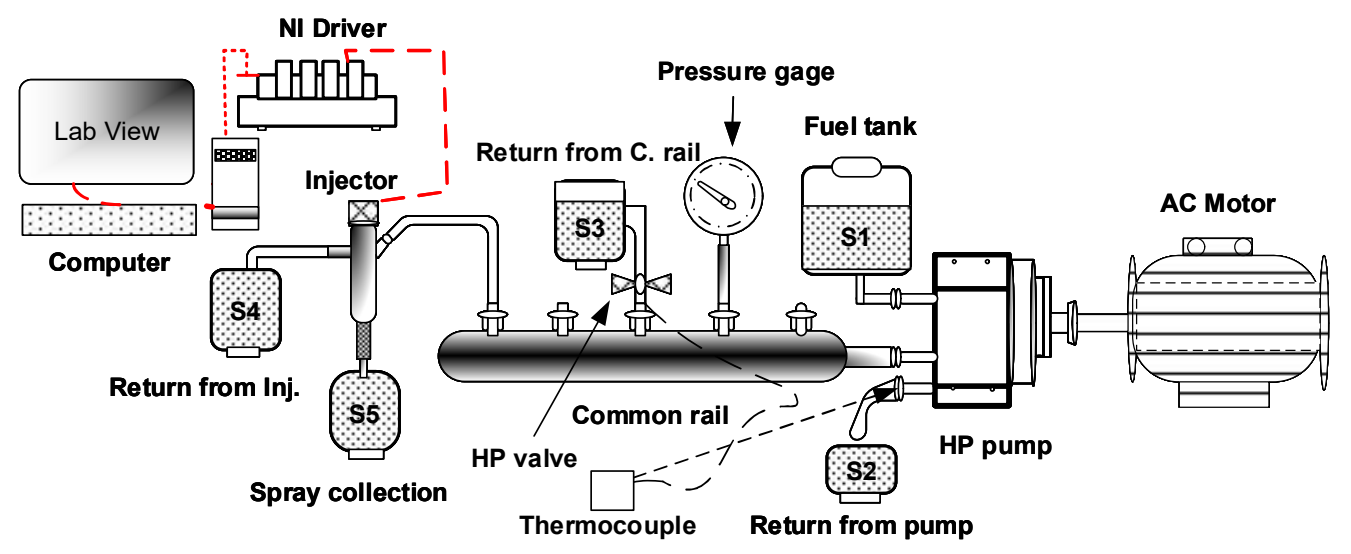

Figure 2. Schematic of the experimental setup. The locations of the five collection points for emulsion samples are labelled S1 to S5. These enabled monitoring of the evolution of the emulsion properties from the fuel tank through to the injection.

\subsubsection{Image acquisition, processing and analysis}

We measured the water content and concentration by measuring the droplet size distribution of the dispersed phase for all samples. We used a microscope (Olympus BX51) with 50× magnification and $10 \mu \mathrm{m}$ depth of field to acquire high-magnification images of the dispersed water droplets. The sampled blends were deposited on a glass plate for analysis. To avoid cross-contamination of the samples, we thoroughly cleaned the glass plate using a solvent between each measurement. To prevent the dissolution of the emulsion's interface by solvent residues, we coated the glass plate with a film of nonpolar oil before depositing a droplet of the emulsion sample. Since the dispersed droplets within the emulsion tend to agglomerate near the glass/emulsion and emulsion/air interfaces, recording the dispersed droplet distribution near these interfaces could result in a biased measurement. To avoid this issue, we focused the microscope half way between the glass/emulsion and emulsion/air interfaces. We acquired images of the dispersed droplets using a digital camera, scanning 10 different physical locations within each sample to obtain statically representative droplet size distributions.

All raw images were then analyzed using a purpose-built MATLAB image processing algorithm to automatically detect the dispersed droplets and measure their sizes. The main steps of the image processing included:

1. Global image threshold using Otsu's method [59] 
2. Dilation of the detected objects, to close some of the translucent droplets' boundaries

3. Filling holes of translucent droplets

4. Erosion of the objects, to correct the dilation performed in step 2

5. Segmentation of the image produced in step 4

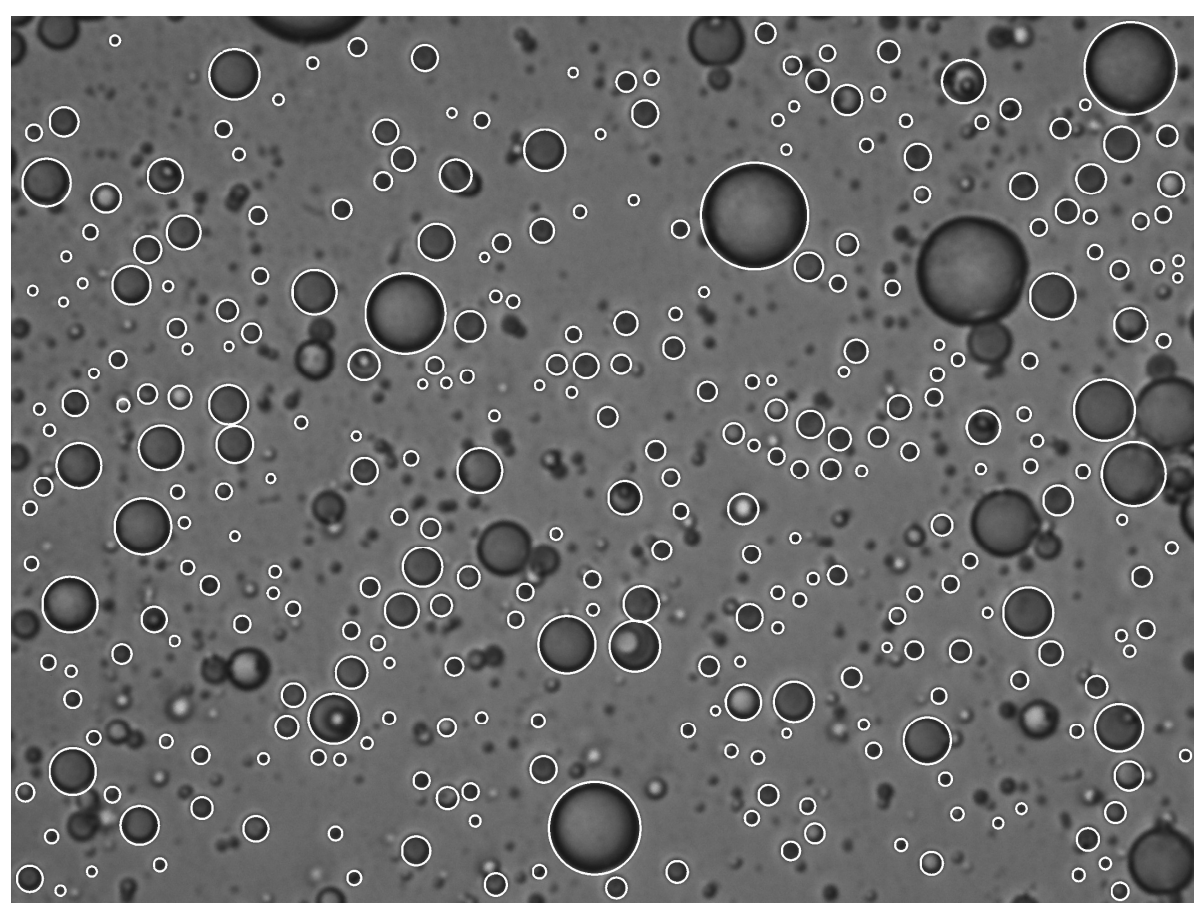

Figure 3. Output from the image processing algorithm. The white circles indicate the droplets that were detected from the acquired image. The algorithm successfully detected most droplets, while discarding out-of-plane defocused droplets, as well as some agglomerates which could not be separated by the watershed transform.

The segmentation performed in step 5 of the algorithm was based on a marker-controlled watershed transform of the Euclidean distance transform of the mask produced in step 4. This approach was used to correctly label agglomerated droplets which were too close to be identified individually using simpler segmentation techniques. The algorithm successfully detected most droplets, while discarding out-of-plane defocused droplets, as well as some agglomerates which could not be separated by the watershed transform (Figure 3). For this particular figure the image processing detected 309 droplets. A visual count indicates that 10 medium and large size droplets were not correctly detected, giving a false-negative detection rate of $3 \%$. Since this detection error is not biased towards a particular droplet size we can confirm that there is no particular bias in the image processing.

Filters were applied onto the detected objects, to remove spurious small and large droplets, to remove noncircular objects, and to remove droplets which were not entirely captured within the image frame. Finally, the equivalent diameter of each detected droplet was calculated based on the droplet's area. Although the image scale factor of the optical system was $44 \mathrm{~nm} /$ pixel, droplets with diameters smaller than 5 pixels were discarded as they could not be fully resolved. Hence the smallest droplet diameter that could be processed by our image processing algorithm was in the order of $250 \mathrm{~nm}$. This equivalent diameter was used to plot the dispersed droplet histograms and water volume content presented in Section 3. 


\section{Results and discussion}

In this section we present evidence that the fuel injection equipment has a small effect on the water concentration of the blends (Section 3.1), due to some water separating or evaporating out of the macro-emulsion. We then demonstrate a significant shift of the size distribution of the dispersed phase towards smaller droplet sizes (Section 3.2). This is caused by the elevated shear and temperatures exerted by the high-pressure pump and the injector's nozzle onto the fuel. We conclude that a large proportion of the water remains within the emulsions either diffused or in the form of a nano-emulsion, rather than as a macro-emulsion.

Table 2. Physical appearance of the samples for 500, 1000 and 1500 bar

\begin{tabular}{cccccc}
\hline $\begin{array}{c}\text { Water content } \\
(\% \mathbf{\%} / \mathbf{v})\end{array}$ & Fuel tank & $\begin{array}{c}\text { HP-pump } \\
\text { return }\end{array}$ & $\begin{array}{c}\text { Common-rail } \\
\text { return }\end{array}$ & $\begin{array}{c}\text { Injector } \\
\text { return }\end{array}$ & $\begin{array}{c}\text { Injector } \\
\text { nozzle }\end{array}$ \\
\hline 5 & semi-translucent & semi-translucent & semi-translucent & semi-translucent & translucent \\
\hline 10 & turbid & turbid & turbid & turbid & semi-translucent \\
\hline 15 & turbid & turbid & turbid & turbid & semi-translucent \\
\hline
\end{tabular}

\subsection{Influence of the injection system on the water concentration}

We operated the injection system and collected five samples for each emulsion blend at 500, 1000 and 1500 bar injection pressure. A visual analysis of the samples confirmed that the 10 and $15 \% \mathrm{v} / \mathrm{v}$ emulsion collected after the injector nozzle were significantly different to the other samples (Table 2). While the initial appearance of these emulsions were turbid, as expected for a macro-emulsion, the appearance of all the emulsion samples became more translucent after injection. This suggests that either a considerable proportion of the water separated (or evaporated) out of the emulsion, or the emulsion shifted to a nano-emulsion with dispersed diameters smaller than $100 \mathrm{~nm}$ [60]. In both cases a fundamental change in the emulsion's properties is required to alter the visual appearance of the samples, which would ultimately impact the mixing and combustion of the blends.

To ascertain whether the emulsion's water had separated out of the blends we measured the density of the samples, and then used a mixing model to compute the water concentration for each sample. This indicated that for the injection conditions which created the highest temperatures and shear (1500 bar injection pressure), the water concentration of the $15 \% \mathrm{v} / \mathrm{v}$ blend reduced to $12.5 \% \mathrm{v} / \mathrm{v}$ after injection (Figure 4). For comparison, the $10 \% \mathrm{v} / \mathrm{v}$ blend was found to contain $9 \% \mathrm{v} / \mathrm{v}$ water after injection. Although these quantities of water loss are not negligible, they represent a relatively small change considering the significant shift in the blends visual appearances.

The change of density between the fuel in the tank and the fuel returning from the high-pressure pump was not significant at 500 bar, but a loss of more than $1 \% \mathrm{v} / \mathrm{v}$ was observed at 1500 bar (Figure 4). This can be explained by the pump and fuel temperatures rise experienced at the higher injection pressures, thus promoting the evaporation of some of the emulsions' water. This evaporation would occur between the pump's return and the tank, hence the water would be lost to the atmosphere and never reincorporated into the blend. Our tests only lasted a few minutes, and we can expect that with recirculation times of hours or days this water loss could be rather non-negligible.

The next sample points after the pump return are the common-rail return, and then the injector return. Interestingly, the blend density further dropped after the common-rail return for all samples at all conditions, but 
the density then increased after the injector return. This would suggest that the water concentration increased between the common-rail and the injector, which is not physically possible as no water was added to the system. We observed that the fuel sampled after the common-rail was considerably hotter than for the other sample locations, reaching $95^{\circ} \mathrm{C}$ at 1500 bar (Figure 5). Although we attempted to rapidly cool down all the samples to inhibit evaporation after their collection, the elevated temperatures found after the common-rail sample point resulted in some water evaporating out of the blends after being collected. This resulted in artificially low water concentrations for that particular sample location in Figure 4. By observing that the densities measured at the pump return and at the injector return are almost identical in all cases, we can conclude that the water concentration did not change inside the common rail.

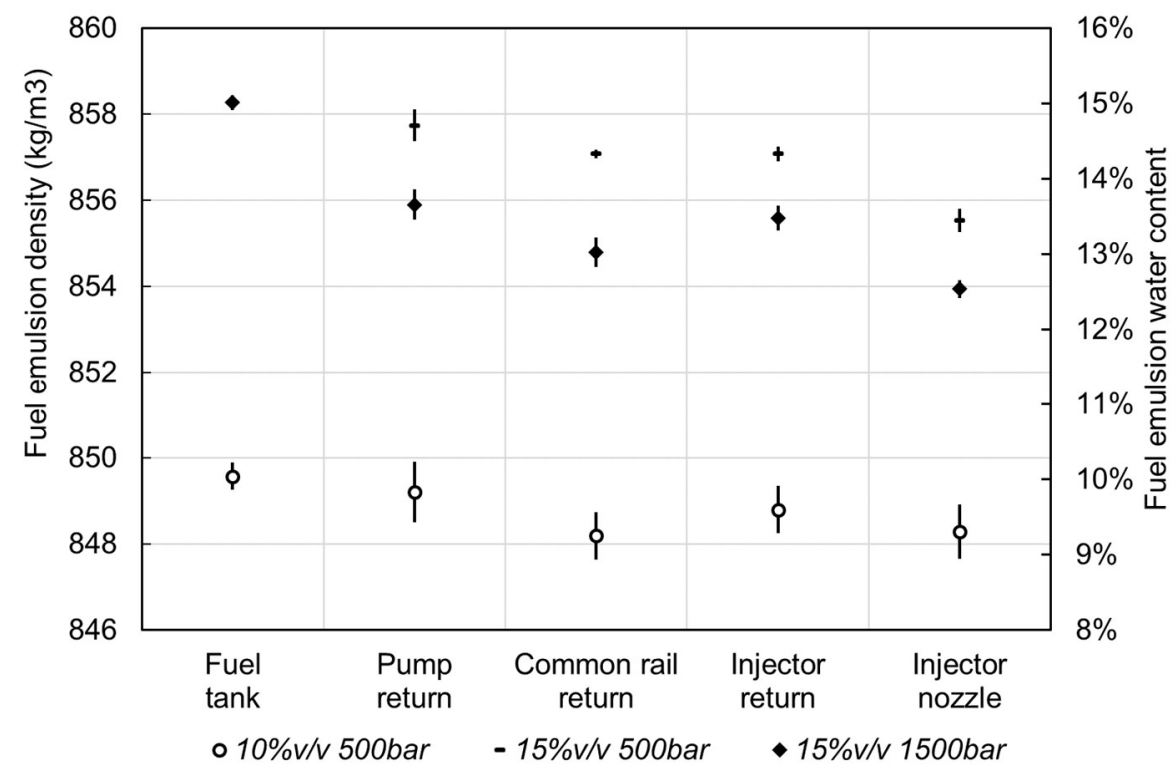

Figure 4. Effect of the injection system components on the density of the emulsified fuel. The density of the fuel reduced after the high-pressure pump, and after the injector nozzle. As the water concentration is linearly related to the emulsion's density, this result indicates that some water separated or evaporated out of the emulsion.

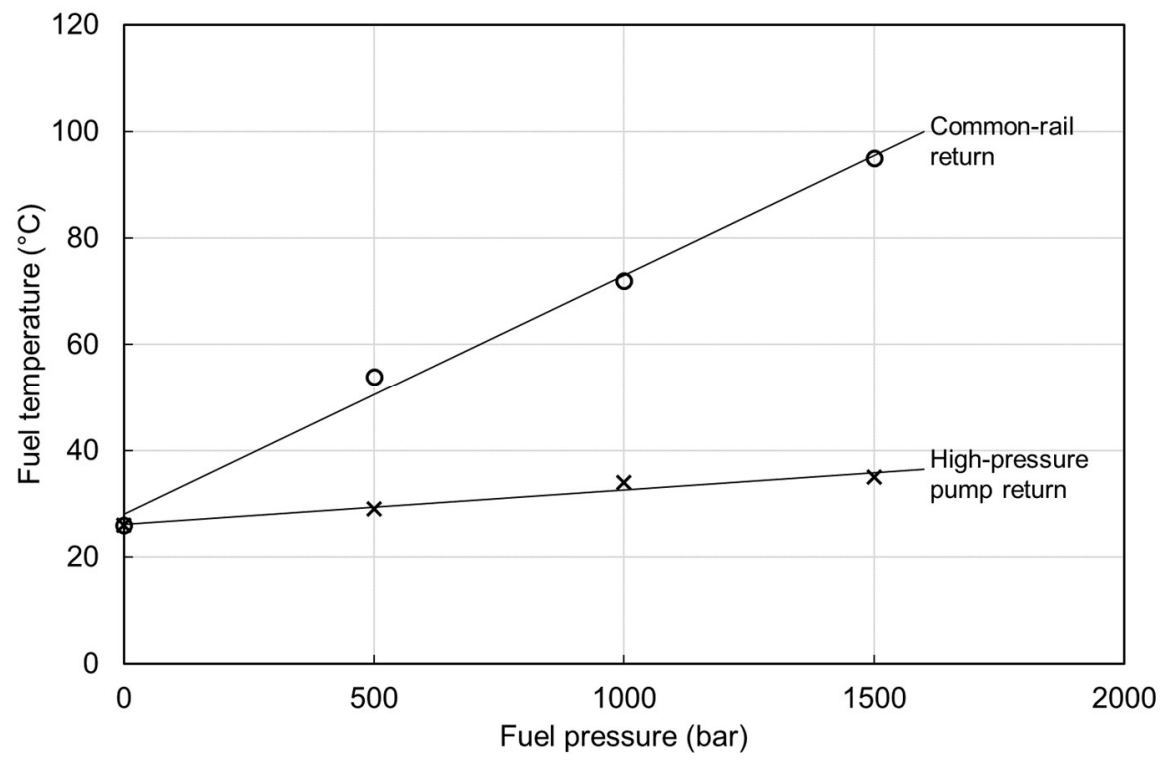


Figure 5. Effect of high pressure pump on temperature of $15 \%$ water content of water-in-diesel emulsion fuel at the exit from the pump return and common rail valve. The initial temperature of the fuel is $26^{\circ} \mathrm{C}$.

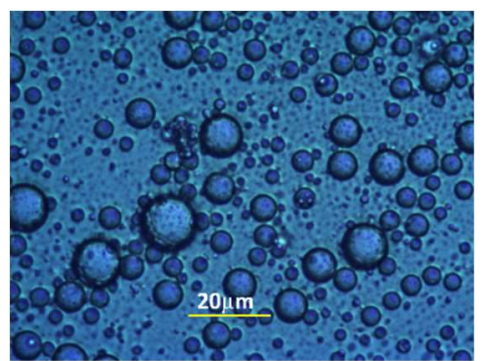

S1: Tank

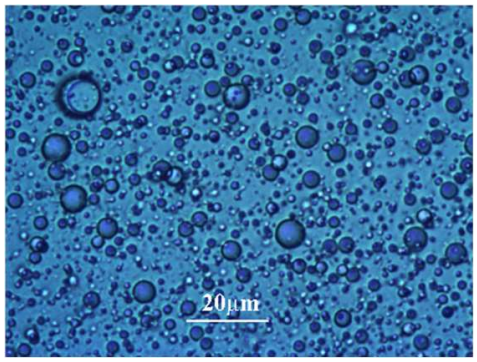

S4: Injector return

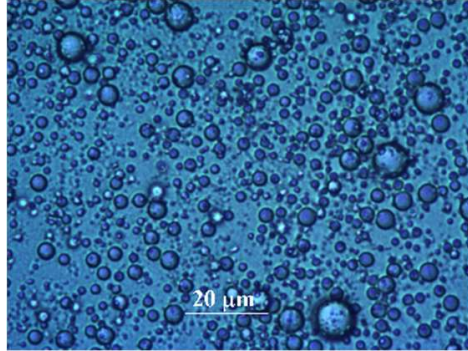

S2: Pump return

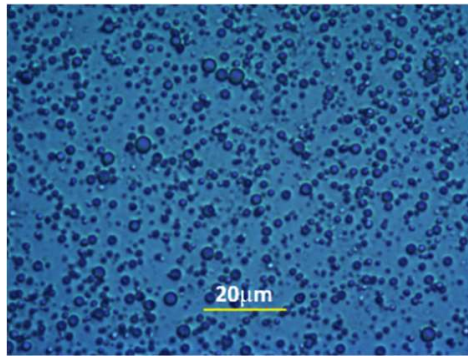

S5: Injector nozzle

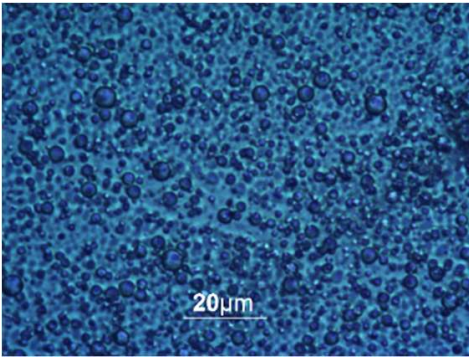

S3: Common-rail return

Figure 6. Images of water-in-diesel emulsion samples for $15 \% \mathrm{v} / \mathrm{v}$ water content, examined under an optical microscope at $50 \times$ magnification for five different sampling locations in the common rail system. The injection pressure was 1000 bar.

The final sample point was after the injector nozzle, by collecting the spray itself. We observed a significant drop in density, suggesting that some of the water was lost through evaporation after being injected. As in the case of the common-rail, it is possible that the water evaporated after the spray samples were collected. However the spray samples cooled down much more rapidly due to the large surface area of the container and the atomization of the fuels. In any case, evaporation of water from the spray would normally occur within the engine cylinder. Hence this water would not be lost, but would contribute to the combustion itself. We note however that the density drop after the nozzle is relatively small, indicating that most of the fuel's water has remained emulsified or diffused within the diesel.

Our analysis confirms that the blends' absolute water concentration did not reduce significantly as a result of the injection system. Hence the change in visual appearance for the fuel sampled at the injector nozzle is not the result of de-emulsification or water evaporation within the injection system, but it is likely due to a change in the properties emulsions' dispersed phase. In the next section we will show that the size distribution of the emulsion's dispersed phase shifted towards much smaller diameters, transforming some of the macro-emulsion into a semitranslucent nano-emulsion.

\subsection{Effect of the injection system on the size distribution of the dispersed water droplets}

The microscope images in Figure 6 show typical samples of the dispersed phase for the $15 \% \mathrm{v} / \mathrm{v}$ emulsion. The samples were collected from five locations (from fuel tank to the injector nozzle) while the injection system was 
running at 1000 bar. We can observe from these images that the fuel returned from the high-pressure pump contained smaller droplets than those found in the tank's fresh emulsion. We can then note that the size distribution further reduced inside the common-rail, but then increased again after the injector return. This suggests that the emulsion is affected by the elevated temperatures in the common-rail, most likely due to viscosity and surface tension being inversely proportional to temperature [61] thus producing small droplets [62], but coalescence then occurs between the rail and the injector line as the fuel cools down [63, 64]. Finally, the spray sampled after the injector nozzle contained very fine droplets compared to the other samples, and a visibly reduced concentration. These images support the findings in the previous section that the most significant changes to the emulsion's properties occur at the high-pressure pump, through elevated pressures and temperatures, and at the injector nozzle through high temperatures and shear.

We processed images of all the samples and produced probability density functions of the dispersed droplet diameters (Figure 7), to unravel the effect of the fuel injection equipment components on the dispersed phase for three injection pressures $(500 ; 1000$ and 1500 bar) and three water content $(5 ; 10$ and $15 \%$ by volume). For all test conditions the fuel pump was found to shift the distributions towards smaller sizes, when compared to the unused emulsion found in the fuel tank. In many cases we can observe that the particularly large droplets found in the tank $(>4 \mu \mathrm{m})$ are no longer present in the other samples, confirming that the high-pressure pump reduced the droplet size distribution. Few differences could be observed between the samples taken from the pump return, common-rail return and injector return. This lack of significant changes to the emulsions is consistent with our results for the visual appearance of the blends (Table 2), for the emulsions' densities (Figure 4), and a qualitative observation of the raw images (Figure 6).

The injector nozzle further shifted the distributions' modes to a smaller diameter, with a general shift from $2 \mu \mathrm{m}$ to $1 \mu \mathrm{m}$. Since micro-explosion of emulsified fuel is sensitive to the cube of the dispersed droplet diameters [65], and the emulsion stability enhanced with smaller droplet size [9], therefore, this reduction in size distribution could significantly reduce the propensity for the emulsion to explode while mixing inside the combustion chamber.

To further illustrate the effect of each component of the fuel injection system on the emulsions we converted the probability density functions (Figure 7) into cumulative density functions (Figure 8). Three classes of distributions clearly emerge: 1) the fuel tank has the largest droplet sizes; 2) the pump, common-rail and injector returns have smaller but similar sizes; 3 ) the post-injection samples taken at the injector nozzle have the smallest dispersed droplet size distribution. This demonstrates that the most significant changes in the emulsion occur first within the fuel pump, and then in the injector nozzle as previously discussed.

In order to estimate the concentration of water in the images of the samples, we computed the volume of every droplet detected by our algorithm. By measuring the depth of field of our microscope $(10 \mu \mathrm{m})$ we could obtain the sampling volume of our instrument. Since the images were shadowgraphs, we needed to account for the fact that droplets larger than the sampling volume would have a disproportionate effect on our volume calculations. This is because the periphery of large droplets would be clearly visible, but along the optical path these droplets would extend beyond the sampling volume, thus incorrectly increasing the computed water concentration. To account for this effect and eliminate the bias towards large droplets, we implemented a slicing model to discard the out of plane volume of all droplets larger than the microscope's depth of field. The image-based water 
concentration can then be compared to the density-based approach we used in Section 3.1. The two approaches gave similar water concentrations for samples taken from the fuel tank (Figure 9), giving confidence that our image-based approach is reasonable. It is interesting to observe that although the total water concentration (measured from the blend density) did not reduce significantly through the injection system, the visible water concentration (measured from the microscope images) showed a very significant reduction of the water content. The significant difference between these two measurements indicates that a large proportion of the emulsion's water is no longer visible as discrete water droplets. It is possible that some of the water has diffused into the fuel, but it is most likely that the high temperatures, pressures and shear present in the fuel injection system have broken up a large proportion of the droplets towards much smaller diameters that could not be resolved by our imagebased technique. In the process, parts of the initial blends were transformed from macro-emulsions into semitranslucent nano-emulsions.

These results suggest that a significant impact for real applications is that the performance and energy efficiency of emulsions used by vehicle fleets will vary with engine running time. With extended operating times the water content of the emulsion returned to the fuel tank will decrease significantly. This drop in the emulsion's water content in the fuel tank will inevitably change the physical and calorific properties of the fuel being injected, which in turn will induce a drift in the engine performance and exhaust emissions, reducing the break thermal efficiency, increasing NOx, smoke and unburnt hydrocarbons emissions [16].
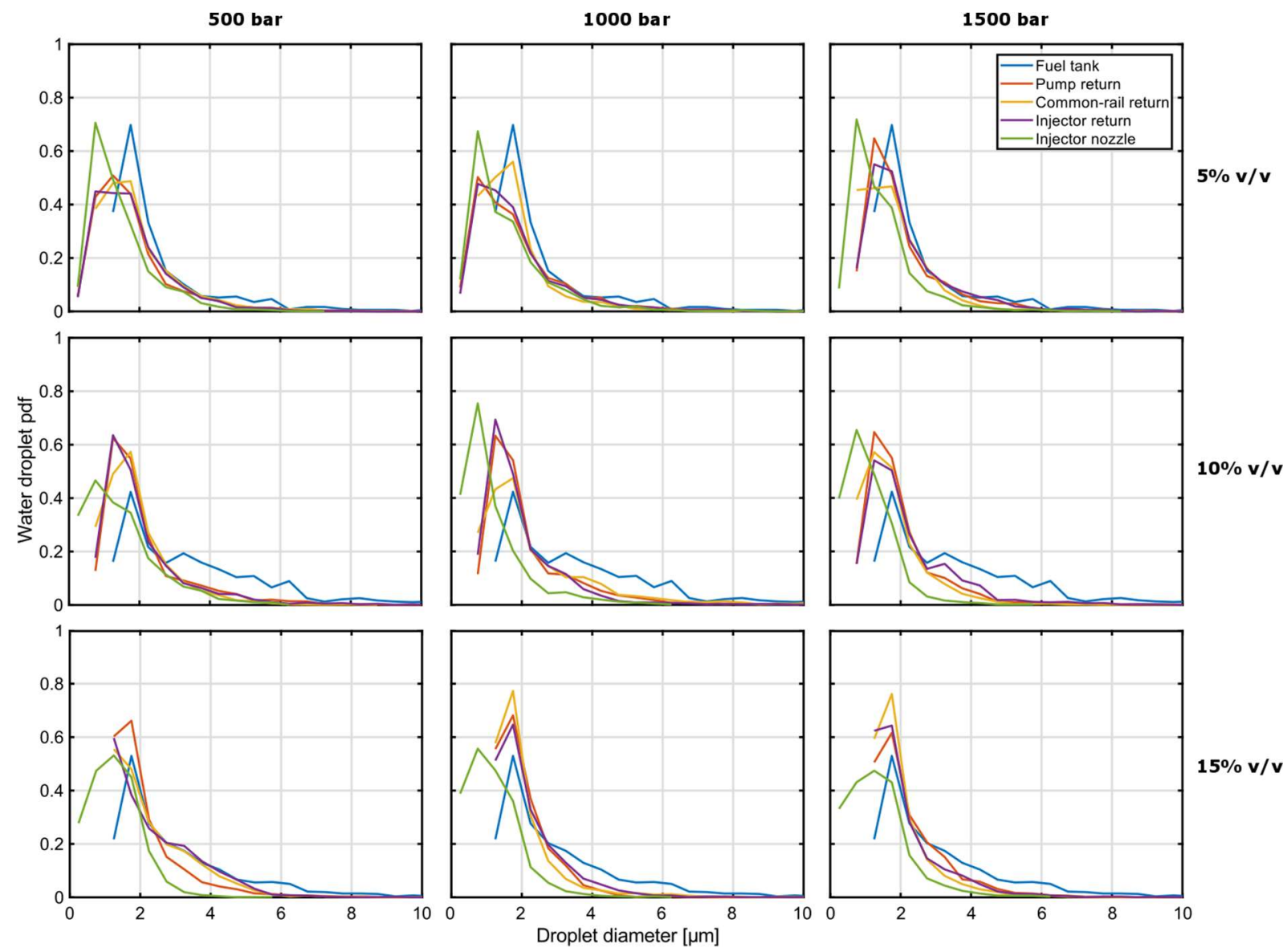

Figure 7. Effect of the fuel injection equipment components on the dispersed water droplets size distribution (probability density function) for three injection pressures (500; 1000 and 1500 bar) and three water content (5; 
10 and $15 \%$ by volume). For all test conditions the fuel pump was found to shift the distributions to smaller sizes, and the injector nozzle further shifted the distributions' modes to a smaller diameter.
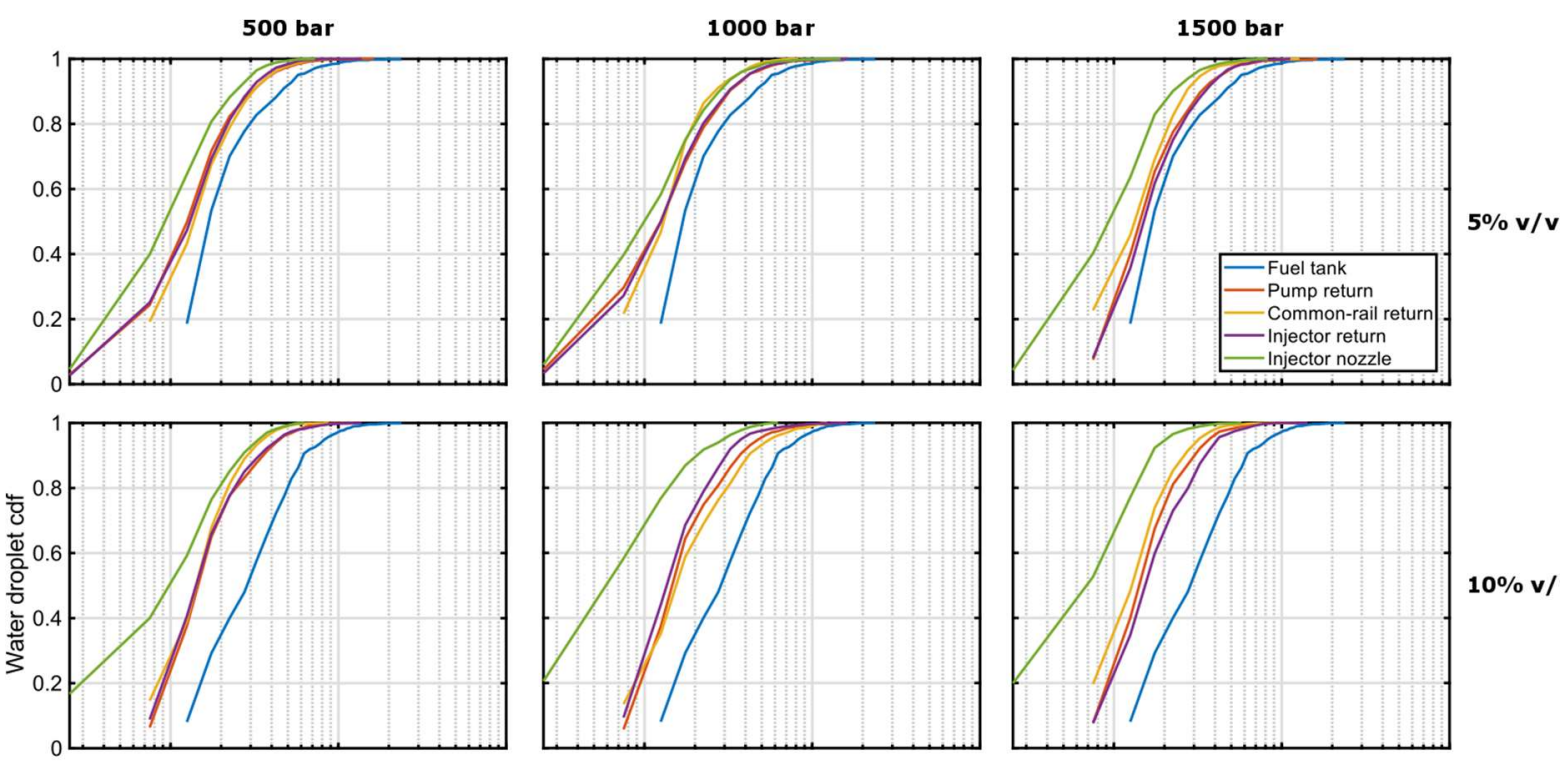

$10 \% \mathrm{v} / \mathrm{v}$
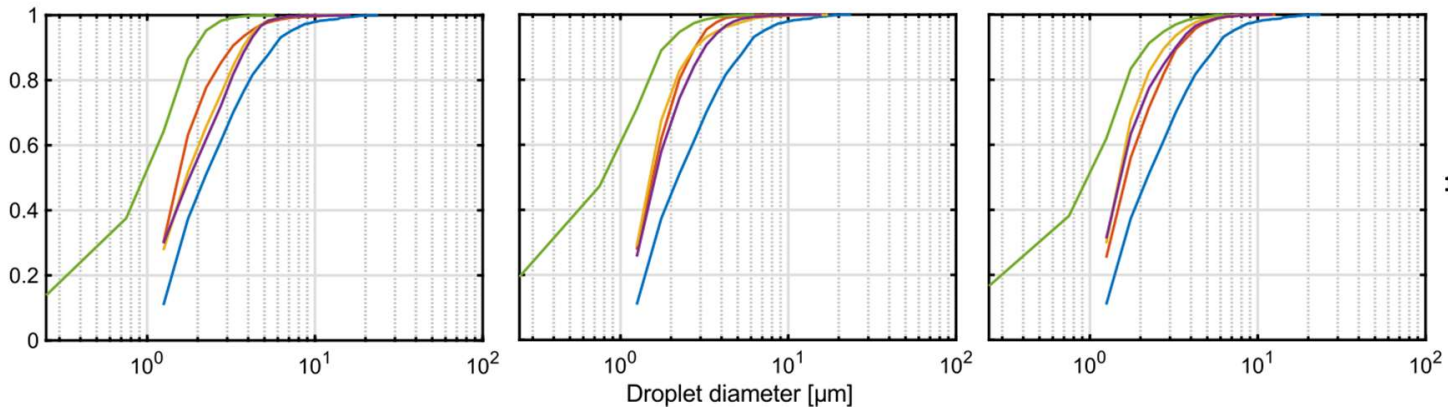

$15 \% \mathrm{v} / \mathrm{v}$

Figure 8. The cumulative density functions show that three main classes of distributions emerge: 1) the fuel tank has the largest droplet sizes; 2) the pump, common-rail and injector returns have smaller but similar sizes; 3) the post-injection samples taken at the injector nozzle have the smallest dispersed droplet size distribution. This demonstrates that the most significant changes in the emulsion occur first within the fuel pump, and then in the injector nozzle. 


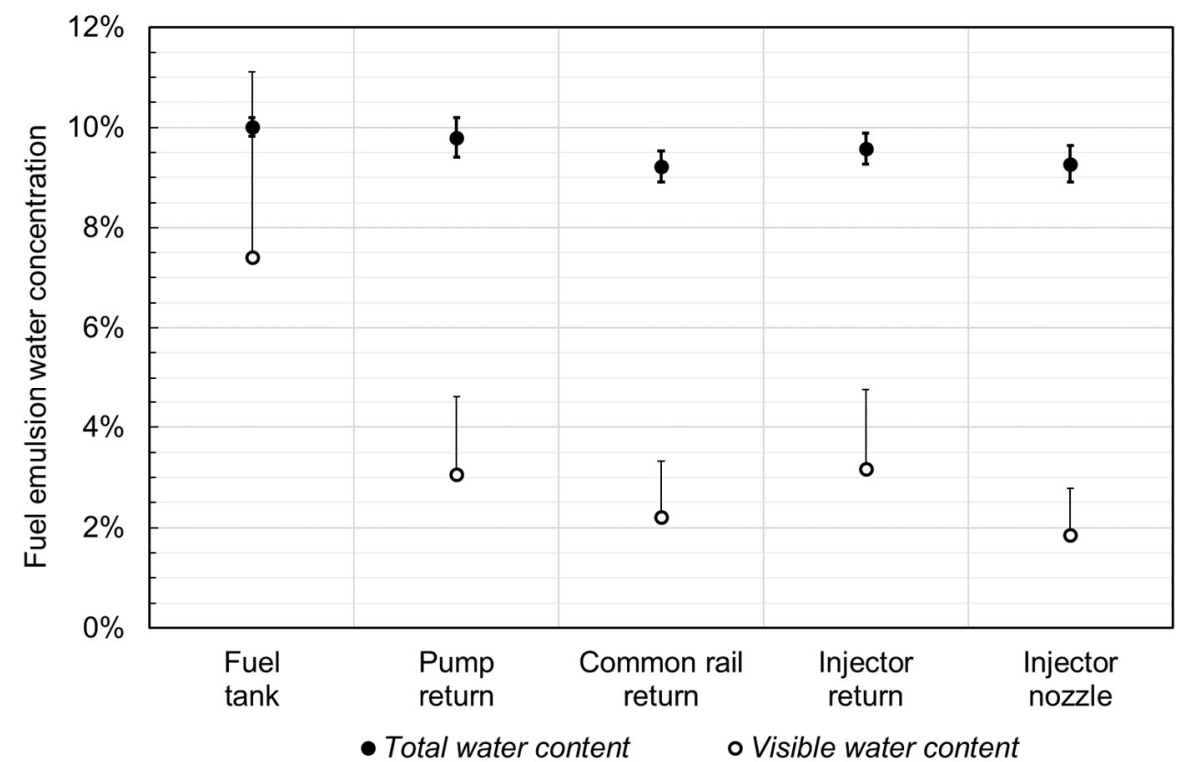

Figure 9. Water content in the fuel for the $10 \% \mathrm{v} / \mathrm{v}$ emulsion blend, injected at $500 \mathrm{bar}$. The total water content (black circles) was obtained from the fuel density measurement. The visible water content (white circles) was measured by microscope image analysis of the samples, and accounts for the dispersed water droplets in the emulsion that could be resolved by our optical system (diameters greater than $250 \mathrm{~nm}$ ). The significant difference between these two measurements indicates that a large proportion of the emulsion's water has is no longer visible as discrete water droplets, indicating that the macro-emulsion has transformed into a nano-emulsion.

\section{Conclusions}

We investigated the effect of a common-rail injection system on the dispersed phase of several water-in-diesel emulsions. We sampled each emulsion at several locations within the injection system, from the fuel tank to the injector nozzle, and measured the evolution of the droplet size distribution of the emulsion's dispersed phase. Our measurements provide new evidence of the evolution of emulsion inside high-pressure injection systems. Significant findings from this study include:

1. The dispersed droplet sizes reduce significantly after the emulsion is compressed by the high-pressure fuel pump, and again after being injected through the nozzle's orifices.

2. The visual appearance of the blends, the emulsions' densities, qualitative and quantitative analysis of the dispersed droplet size distributions all confirm that the macro-emulsion turns into a nano-emulsion after the injector nozzle.

3. The dispersed droplet sizes measured from the pump's return and injector return to the fuel tank were also smaller than the initial sizes, suggesting that the physical and calorific properties of the emulsion in the fuel tank can change significantly with time.

As a result of this study we propose that differences in injection equipment, and engine testing duration, may contribute to some of the disagreements in the literature regarding the effect of emulsified fuels on engine emissions. Our findings also show that computing BSFC using the nominal calorific value (i.e. water content) of an emulsion could be misleading as this neglects the fact that the engine's fuel system promotes the de- 
emulsification and the loss of water through heating and shearing of the emulsion. Since the exact water content of an injected emulsion will depend on operating conditions as well as injection hardware specifications, we recommend computing BSFC based on an emulsion's fuel content only. Another significant consequence for vehicle fleets that use emulsified fuels is that the physical and calorific properties of the emulsion in their tanks will change with engine running time, thus potentially inducing a drift in fuel consumption, engine performance and exhaust emissions with time.

This investigation also suggests that, in order to be representative of actual injection conditions, fundamental studies of the micro-explosion of emulsion droplets should be performed using much smaller dispersed droplet sizes than those normally found in an unused emulsion.

\section{Acknowledgements}

The authors would like to acknowledge the support given by the Universiti Teknologi Petronas to the Centre for Automotive Research and Electric Mobility in performing this research. S.I.T Schiffs \& Industrie Technik (M) Sdn Bhd is also acknowledged for providing the emulsion samples. The authors express their gratitude to $\mathrm{Mr}$. Mahfuzrazi and Mr. Shahrul for their assistance in conducting the experiments. This work was supported by the UK's Engineering and Physical Science Research Council [grants EP/K020528/1 and EP/M009424/1].

\section{References}

[1] S. H. Park and S. H. Yoon, "Injection strategy for simultaneous reduction of NOx and soot emissions using two-stage injection in DME fueled engine," Appl. Energy, vol. 143, no. x, pp. 262-270, 2015, doi:10.1016/j.apenergy.2015.01.049.

[2] X. Ma, F. Zhang, K. Han, Z. Zhu, and Y. Liu, "Effects of intake manifold water injection on combustion and emissions of diesel engine," in Energy Procedia, 2014, vol. 61, pp. 777-781.

[3] E. Arabaci, Y. İçingür, H. Solmaz, A. Uyumaz, and E. Yilmaz, "Experimental investigation of the effects of direct water injection parameters on engine performance in a six-stroke engine," Energy Convers. Manag., vol. 98, pp. 89-97, Jul. 2015, doi:10.1016/J.ENCONMAN.2015.03.045.

[4] F. Bedford, C. Rutland, P. Dittrich, and F. Wirbeleit, "Effects of direct water injection on di diesel engine combustion," SAE Pap. 01-2938, 2000.

[5] A. Farfaletti et al., "Effect of Water/Fuel Emulsions and a Cerium-Based Combustion Improver Additive on HD and LD Diesel Exhaust Emissions," Environ. Sci. Technol., vol. 39, no. 17, pp. 67926799, 2005, doi:10.1021/es048345v.

[6] M. A. Ismael, M. R. Heikal, A. Rashid, A. Aziz, and C. Crua, “An overview of experimental techniques of the investigation of water-diesel emulsion characteristics droplets micro-explosion," ARPN J. Eng. Appl. Sci., vol. 11, no. 20, 2016.

[7] A. M. Ithnin, M. A. Ahmad, M. A. A. Bakar, S. Rajoo, and W. J. Yahya, "Combustion performance and emission analysis of diesel engine fuelled with water-in-diesel emulsion fuel made from low-grade diesel fuel," Energy Convers. Manag., vol. 90, pp. 375-382, 2015, doi:10.1016/j.enconman.2014.11.025.

[8] L. Feng, B. Du, J. Tian, W. Long, and B. Tang, "Combustion performance and emission characteristics of a diesel engine using a water-emulsified heavy fuel oil and light diesel blend," Energies, vol. 8, no. 12, pp. 13628-13640, 2015, doi:10.3390/en81212387.

[9] W. M. Yang et al., "Impact of emulsion fuel with nano-organic additives on the performance of diesel engine," Appl. Energy, vol. 112, pp. 1206-1212, 2013, doi:10.1016/j.apenergy.2013.02.027.

[10] M. E. A. Fahd, Y. Wenming, P. S. Lee, S. K. Chou, and C. R. Yap, "Experimental investigation of the performance and emission characteristics of direct injection diesel engine by water emulsion diesel 
under varying engine load condition," Appl. Energy, vol. 102, pp. 1042-1049, 2013, doi:10.1016/j.apenergy.2012.06.041.

[11] A. M. Ithnin, H. Noge, H. Abdul Kadir, and W. Jazair, "An overview of utilizing water-in-diesel emulsion fuel in diesel engine and its potential research study," J. Energy Inst., vol. 87, no. 4, pp. $273-$ 288, Nov. 2014, doi:10.1016/j.joei.2014.04.002.

[12] M. Nadeem, C. Rangkuti, K. Anuar, M. R. U. Haq, I. B. Tan, and S. S. Shah, "Diesel engine performance and emission evaluation using emulsified fuels stabilized by conventional and gemini surfactants," Fuel, vol. 85, no. 14-15, pp. 2111-2119, Oct. 2006, doi:10.1016/J.FUEL.2006.03.013.

[13] O. Armas, R. Ballesteros, F. J. J. Martos, and J. R. R. Agudelo, "Characterization of light duty Diesel engine pollutant emissions using water-emulsified fuel," Fuel, vol. 84, no. 7-8, pp. 1011-1018, May 2005.

[14] A. M. Ithnin et al., "Emulsifier-free Water-in-Diesel emulsion fuel: Its stability behaviour, engine performance and exhaust emission," Fuel, vol. 215, no. November 2017, pp. 454-462, 2018, doi:10.1016/j.fuel.2017.11.061.

[15] N. A. Mazlan et al., "Effects of different water percentages in non-surfactant emulsion fuel on performance and exhaust emissions of a light-duty truck," J. Clean. Prod., vol. 179, no. x, pp. 559-566, 2018, doi:10.1016/j.jclepro.2018.01.143.

[16] O. A. Elsanusi, M. M. Roy, and M. S. Sidhu, "Experimental Investigation on a Diesel Engine Fueled by Diesel-Biodiesel Blends and their Emulsions at Various Engine Operating Conditions," Appl. Energy, vol. 203, pp. 582-593, Oct. 2017, doi:10.1016/j.apenergy.2017.06.052.

[17] J. K. Mwangi, W.-J. Lee, Y.-C. Chang, C.-Y. Chen, and L.-C. Wang, "An overview: Energy saving and pollution reduction by using green fuel blends in diesel engines," Appl. Energy, vol. 159, pp. 214-236, Dec. 2015, doi:10.1016/j.apenergy.2015.08.084.

[18] M. Abu-Zaid, "Performance of single cylinder, direct injection Diesel engine using water fuel emulsions," Energy Convers. Manag., vol. 45, no. 5, pp. 697-705, Mar. 2004, doi:10.1016/S01968904(03)00179-1.

[19] Y. Xu, P. Hellier, S. Purton, F. Baganz, and N. Ladommatos, "Algal biomass and diesel emulsions: An alternative approach for utilizing the energy content of microalgal biomass in diesel engines," Appl. Energy, vol. 172, pp. 80-95, Jun. 2016, doi:10.1016/j.apenergy.2016.03.019.

[20] D. Ogunkoya, S. Li, O. J. Rojas, and T. Fang, "Performance, combustion, and emissions in a diesel engine operated with fuel-in-water emulsions based on lignin," Appl. Energy, vol. 154, pp. 851-861, 2015, doi:10.1016/j.apenergy.2015.05.036.

[21] H. Taghavifar, S. Anvari, and A. Parvishi, "Benchmarking of water injection in a hydrogen-fueled diesel engine to reduce emissions," Int. J. Hydrogen Energy, vol. 42, no. 16, pp. 11962-11975, 2017, doi:10.1016/j.ijhydene.2017.02.138.

[22] B. K. Debnath, U. K. Saha, and N. Sahoo, "A comprehensive review on the application of emulsions as an alternative fuel for diesel engines," Renew. Sustain. Energy Rev., vol. 42, pp. 196-211, 2015, doi:10.1016/j.rser.2014.10.023.

[23] C. Y. Lin and L. W. Chen, "Comparison of fuel properties and emission characteristics of two- and three-phase emulsions prepared by ultrasonically vibrating and mechanically homogenizing emulsification methods," Fuel, vol. 87, no. 10-11, pp. 2154-2161, 2008, doi:10.1016/j.fuel.2007.12.017.

[24] A. M. A. Attia and A. R. Kulchitskiy, "Influence of the structure of water-in-fuel emulsion on diesel engine performance," Fuel, vol. 116, pp. 703-708, 2014, doi:10.1016/j.fuel.2013.08.057.

[25] D. R. Emberson, B. Ihracska, S. Imran, and A. Diez, "Optical characterization of Diesel and water emulsion fuel injection sprays using shadowgraphy," Fuel, vol. 172, no. x, pp. 253-262, 2016, doi:10.1016/j.fuel.2016.01.015.

[26] Y.-C. Chang, W.-J. Lee, S.-L. Lin, and L.-C. Wang, "Green energy: Water-containing acetone-butanolethanol diesel blends fueled in diesel engines," Appl. Energy, vol. 109, pp. 182-191, Sep. 2013, doi:10.1016/J.APENERGY.2013.03.086.

[27] S. H. Pourhoseini and R. Esmaeeli, "Effect of nanosilver/water-in-kerosene emulsion on nox reduction 
and enhancement of thermal characteristics of a liquid fuel burner," Energy \& Fuels, vol. 31, no. 12, pp. 14288-14295, 2017, doi:10.1021/acs.energyfuels.7b02981.

[28] J. Shinjo, J. Xia, L. C. Ganippa, and A. Megaritis, "Physics of puffing and microexplosion of emulsion fuel droplets," Phys. Fluids, vol. 26, no. 10, 2014, doi:10.1063/1.4897918.

[29] T. Daho et al., "Influence of engine load and fuel droplet size on performance of a CI engine fueled with cottonseed oil and its blends with diesel fuel," Appl. Energy, vol. 111, pp. 1046-1053, 2013, doi:10.1016/j.apenergy.2013.05.059.

[30] T. Kadota, H. Tanaka, D. Segawa, S. Nakaya, and H. Yamasaki, "Microexplosion of an emulsion droplet during Leidenfrost burning," Proc. Combust. Inst., vol. 31 II, pp. 2125-2131, 2007, doi:10.1016/j.proci.2006.07.001.

[31] M. Huo, S. Lin, H. Liu, and C. F. Lee, "Study on the spray and combustion characteristics of wateremulsified diesel," Fuel, vol. 123, pp. 218-229, May 2014, doi:10.1016/j.fuel.2013.12.035.

[32] J. W. Park, K. Y. Huh, and K. H. Park, "Experimental study on the combustion characteristics of emulsified diesel in a rcem," Seoul 2000 FISITA World Automot. Congr., no. 6, pp. 1-6, 2000.

[33] H. Watanabe and K. Okazaki, "Visualization of secondary atomization in emulsified-fuel spray flow by shadow imaging," Proc. Combust. Inst., vol. 34, no. 1, pp. 1651-1658, Jan. 2013, doi:10.1016/j.proci.2012.07.005.

[34] H. Watanabe, Y. Shoji, T. Yamagaki, J. Hayashi, F. Akamatsu, and K. Okazaki, "Secondary atomization and spray flame characteristics of carbonated W/O emulsified fuel," Fuel, vol. 182, pp. 259-265, Oct. 2016, doi:10.1016/j.fuel.2016.05.121.

[35] S. Park, S. Woo, H. Kim, and K. Lee, "The characteristic of spray using diesel water emulsified fuel in a diesel engine,” Appl. Energy, vol. 176, pp. 209-220, 2016, doi:10.1016/j.apenergy.2016.05.069.

[36] T. Niioka and J. Sato, "Combustion and microexplosion behavior of miscible fuel droplets under high pressure," Symp. Combust., vol. 21, no. 1, pp. 625-631, Jan. 1988, doi:10.1016/S0082-0784(88)802935.

[37] R. Ochoterena, A. Lif, M. Nydén, S. Andersson, and I. Denbratt, "Optical studies of spray development and combustion of water-in-diesel emulsion and microemulsion fuels," Fuel, vol. 89, no. 1, pp. 122 132, 2010, doi:10.1016/j.fuel.2009.06.039.

[38] M. Zhu, Z. Zhang, Y. Zhang, P. Liu, and D. Zhang, "An experimental investigation into the ignition and combustion characteristics of single droplets of biochar water slurry fuels in air," Appl. Energy, vol. 185, pp. 2160-2167, 2017, doi:10.1016/j.apenergy.2015.11.087.

[39] B. Kichatov, A. Korshunov, A. Kiverin, and A. Saveliev, "The role of explosive boiling in the process of foamed emulsion combustion," Int. J. Heat Mass Transf., vol. 119, pp. 199-207, 2018, doi:10.1016/j.ijheatmasstransfer.2017.11.116.

[40] D. Tarlet, E. Mura, C. Josset, J. Bellettre, C. Allouis, and P. Massoli, "Distribution of thermal energy of child-droplets issued from an optimal micro-explosion," Int. J. Heat Mass Transf., vol. 77, pp. 10431054, 2014, doi:10.1016/j.ijheatmasstransfer.2014.06.054.

[41] V. Califano, R. Calabria, and P. Massoli, "Experimental evaluation of the effect of emulsion stability on micro-explosion phenomena for water-in-oil emulsions," Fuel, vol. 117, pp. 87-94, 2014, doi:10.1016/j.fuel.2013.08.073.

[42] E. Mura, P. Massoli, C. Josset, K. Loubar, and J. Bellettre, "Study of the micro-explosion temperature of water in oil emulsion droplets during the Leidenfrost effect," Exp. Therm. Fluid Sci., vol. 43, pp. 6370, 2012, doi:10.1016/j.expthermflusci.2012.03.027.

[43] I. Jeong, K.-H. Lee, and J. Kim, "Characteristics of auto-ignition and micro-explosion behavior of a single droplet of water-in-fuel," J. Mech. Sci. Technol., vol. 22, no. 1, pp. 148-156, 2008, doi:10.1007/s12206-007-1018-5.

[44] M. Y. Khan, Z. A. A. Karim, A. R. A. Aziz, and I. M. Tan, "A case study on the influence of selected parameters on microexplosion behavior of water in biodiesel emulsion droplets," J. Energy Resour. Technol., vol. 139, no. 2, pp. 1-10, 2017, doi:10.1115/1.4034230.

[45] Y. Kimoto, K., Owashi, Y., \& Omae, "The vaporizing behavior of the fuel droplet of water-in-oil emulsion on the hot surface," Bull. JSME, vol. 258, no. 29, pp. 4247-4255, 1986, 
doi:10.1248/cpb.37.3229.

[46] E. Mura, C. Josset, K. Loubar, G. Huchet, and J. Bellettre, "Effect of dispersed water droplet size in microexplosion phenomenon for water in oil emulsion,” At. Sprays, vol. 20, no. 9, pp. 791-799, 2010, doi:10.1615/AtomizSpr.v20.i9.40.

[47] M. Y. Khan, Z. A. A. Karim, A. R. A. Aziz, and I. M. Tan, "Experimental investigation of microexplosion occurrence in water in diesel emulsion droplets during the Leidenfrost effect," Energy \& Fuels, vol. 28, no. 11, pp. 7079-7084, 2014, doi:10.1021/ef501588z.

[48] R. Ocampo-Barrera, R. Villasenor, and A. Diego-Marin, "An experimental study of the effect of water content on combustion of heavy fuel oil/water emulsion droplets," Combust. Flame, vol. 126, no. 4, pp. 1845-1855, 2001, doi:10.1016/S0010-2180(01)00295-4.

[49] D. Sechremeli, A. Stampouli, and M. Stamatoudis, "Comparison of mean drop sizes and drop size distributions in agitated liquid-liquid dispersions produced by disk and open type impellers," Chem. Eng. J., vol. 117, no. 2, pp. 117-122, 2006, doi:10.1016/j.cej.2005.12.015.

[50] S. Mohan and G. Narsimhan, "Coalescence of protein-stabilized emulsions in a high-pressure homogenizer,” J. Colloid Interface Sci., vol. 192, no. 192, pp. 1-15, 1997, doi:10.1006/jcis.1997.5012.

[51] G. M. Jang and N. Il Kim, "Relationships between dynamic behavior and properties of a single droplet of water-emulsified n-dodecane," Fuel, vol. 220, no. December 2017, pp. 130-139, 2018, doi:10.1016/j.fuel.2018.01.036.

[52] J. Shinjo, J. Xia, A. Megaritis, L. C. Ganippa, and R. F. Cracknell, "Modeling temperature distribution inside an emulsion fuel droplet under convective heating: A key to predicting microexplosion and puffing," At. Sprays, vol. 26, no. 6, pp. 551-583, 2016, doi:10.1615/AtomizSpr.2015013302.

[53] S. S. Reham, H. H. Masjuki, M. A. Kalam, I. Shancita, I. M. Rizwanul Fattah, and A. M. Ruhul, "Study on stability, fuel properties, engine combustion, performance and emission characteristics of biofuel emulsion," Renew. Sustain. Energy Rev., vol. 52, pp. 1566-1579, Dec. 2015, doi:10.1016/j.rser.2015.08.013.

[54] B. K. Debnath, U. K. Saha, and N. Sahoo, "An Experimental Way of Assessing the Application Potential of Emulsified Palm Biodiesel Toward Alternative to Diesel," J. Eng. Gas Turbines Power, vol. 136, no. 2, p. 21401, Nov. 2013, doi:10.1115/1.4025479.

[55] C. Y. Lin and S. A. Lin, "Effects of emulsification variables on fuel properties of two- and three-phase biodiesel emulsions," Fuel, vol. 86, no. 1-2, pp. 210-217, 2007, doi:10.1016/j.fuel.2006.06.007.

[56] M. A. Ismael, M. R. Heikal, and M. B. Baharom, "Spray Characteristics of a Diesel-CNG Dual Fuel Jet Using The Schlieren Imaging Technique,” Int. J. Mater. Mech. Manuf., vol. 3, no. 3, pp. 145-151, 2015, doi:10.7763/IJMMM.2015.V3.184.

[57] Y. Suzuki et al., "Visualization of aggregation process of dispersed water droplets and the effect of aggregation on secondary atomization of emulsified fuel droplets," Proc. Combust. Inst., vol. 33, no. 2, pp. 2063-2070, Jan. 2011, doi:10.1016/J.PROCI.2010.05.115.

[58] D. Segawa, H. Yamasaki, T. Kadota, H. Tanaka, H. Enomoto, and M. Tsue, "Water-coalescence in an oil-in-water emulsion droplet burning under microgravity," Proc. Combust. Inst., vol. 28, no. 1, pp. 985-990, Jan. 2000, doi:10.1016/S0082-0784(00)80305-7.

[59] N. Otsu, "A threshold selection method from gray-level histograms," IEEE Trans. Syst. Man. Cybern., vol. 9, no. 1, pp. 62-66, 1979, doi:10.1109/TSMC.1979.4310076.

[60] D. J. McClements, "Nanoemulsions versus microemulsions: terminology, differences, and similarities," Soft Matter, vol. 8, no. 6, pp. 1719-1729, 2012, doi:10.1039/C2SM06903B.

[61] T. Al-Wahaibi, Y. Al-Wahaibi, A.-A. R. A. R. Al-Hashmi, F. S. Mjalli, and S. Al-Hatmi, "Experimental investigation of the effects of various parameters on viscosity reduction of heavy crude by oil-water emulsion," Pet. Sci., vol. 12, no. 1, pp. 170-176, Mar. 2015, doi:10.1007/s12182-014-0009-2.

[62] J. Floury, A. Desrumaux, and J. Lardières, "Effect of high-pressure homogenization on droplet size distributions and rheological properties of model oil-in-water emulsions," Innov. Food Sci. Emerg. Technol., vol. 1, no. 2, pp. 127-134, 2000, doi:10.1016/S1466-8564(00)00012-6.

[63] S. M. Jafari, E. Assadpoor, Y. He, and B. Bhandari, "Re-coalescence of emulsion droplets during highenergy emulsification," Food Hydrocoll., vol. 22, no. 7, pp. 1191-1202, Oct. 2008, 
doi:10.1016/j.foodhyd.2007.09.006.

[64] J. Chen and P. Zhang, "Preparation and characterization of nano-sized phase change emulsions as thermal energy storage and transport media," Appl. Energy, vol. 190, pp. 868-879, 2017, doi:10.1016/j.apenergy.2017.01.012.

[65] W. B. Fu, L. Y. Hou, L. Wang, and F. H. Ma, "A unified model for the micro-explosion of emulsified droplets of oil and water," Fuel Process. Technol., vol. 79, no. 2, pp. 107-119, 2002, doi:10.1016/S0378-3820(02)00106-6. 